\title{
Angiotensin-converting enzyme gene D-allele and the severity of coronary artery disease
}

\author{
MARIA-CRISTINA VLADEANU ${ }^{1}$, IRIS BARARU BOJAN ${ }^{1}$, ANDREI BOJAN $^{2}$, DAN ILIESCU ${ }^{3}$, \\ MINERVA CODRUTA BADESCU ${ }^{3}$, OANA VIOLA BADULESCU ${ }^{1}$, MAGDA BADESCU ${ }^{1}$, \\ CATALINA ARSENESCU GEORGESCU ${ }^{3}$ and MANUELA CIOCOIU ${ }^{1}$
}

\author{
Departments of ${ }^{1}$ Physiopathology, ${ }^{2}$ Surgical Sciences and ${ }^{3}$ Internal Medicine, \\ 'Grigore T. Popa' University of Medicine and Pharmacy, 700115 Iasi, Romania
}

Received May 15, 2020; Accepted June 16, 2020

DOI: $10.3892 / \mathrm{etm} .2020 .8978$

\begin{abstract}
Coronary artery disease (CAD) is the first cause of morbidity and mortality worldwide. An important goal is to diagnose patients in early stages, in order to reduce acute cardiovascular events. The angiotensin-converting enzyme (ACE) is an important element for the cardiovascular system, through its actions on hydro-salin balance and vascular tone. ACE polymorphism consists of insertions (I)/deletions (D) and there are 3 genotypes: II, ID, DD. It is speculated that the DD genotype may be a genetic basis for severe CAD, while the II genotype may have a protective effect on the coronary arteries. The present study included 154 patients with acute coronary syndroms admitted to the Institute for Cardiovascular Disease 'George I.M. Georgescu', Iasi. The patients underwent coronary angiography in order to assess the severity of the lesions and the ACE genotypes were determined for each patient. The genotypes were correlated with the severity of the vessel-disease and the exposure to classic risk factors. It was concluded that the D-allele is associated with a greater risk for acute coronary events and severe coronary stenosis, especially when risk genotype and risk phenotype interact.
\end{abstract}

\section{Introduction}

Coronary artery disease (CAD) is the first cause of morbidity and mortality all around the world. During the last 30 years,

Correspondence to: Dr Minerva Codruta Badescu, Department of Internal Medicine, 'Grigore T. Popa' University of Medicine and Pharmacy, 16 Universitatii Street, 700115 Iasi, Romania

E-mail: codruta.badescu@gmail.com

Dr Iris Bararu Bojan, Department of Physiopathology, 'Grigore T. Popa' University of Medicine and Pharmacy, 16 Universitatii Street, 700115 Iasi, Romania

E-mail: iris_bararu@yahoo.com

Key words: angiotensin-converting enzyme gene, gene polymorphism, D-allele, I-allele, coronary artery disease, unstable angina, acute myocardial infarction important progress was made in order to reduce the morbi-mortality of atherosclerotic disease. Correction of cardiovascular risk factors and improving treatments for acute coronary syndromes have represented the first line of study. An important goal is to diagnose patients in early stages, in order to reduce acute cardiovascular events. Latest discoveries revealed that mutations in the angiotensin-converting enzyme (ACE) gene may influence the onset and the severity of CAD (1). Therefore, studying the association between genotype and phenotype would be an important cornerstone in cardiology.

The angiotensin-converting enzyme is common to RAAS (renin-angiotensin-aldosterone system) and the kinin-kalicrein system. ACE is a zinc metalloproteinase that cleaves the terminal dipeptide (His-Leu) of Ang I, turning it into Ang II, a highly constricting substance. Due to interference on the two systems, ACE also inactivates bradykinin, a vasodilating substance. Through its functions, ACE maintains the hydro-salin balance and vascular tone $(2,3)$.

The ACE gene is found on the long arm of chromosome 17, at heading 23 (17q23), measures $21 \mathrm{~kb}$ and includes 26 exons and 25 introns (4).

ACE polymorphism consists of insertions (I)/deletions (D) at the level of intron 16. Thus, from the polymorphism of intron 16, there are 3 genotypes: Insertional homozygote (II), heterozygote (ID) and teletional homozygote (DD). Serum levels of ACE are determined by genetic polymorphism in the following order: DD>ID>II.

The central goal of our study was to investigate the correlation between the presence of the D-allele and severe stenosis or occlusion of one or several coronary arteries.

\section{Patients and methods}

The present study included 154 patients with acute coronary syndroms (acute myocardial infarction and unstable angina) admitted to the Institute for Cardiovascular Disease 'George I.M. Georgescu', Iasi. The study was approved by the Ethics Committee of the 'Grigore T. Popa' University of Medicine and Pharmacy (Iasi, Romania) on 09.06.2015, according to the law of medical research, no. 206 from 27.05.2004. Informed consent was obtained from all patients included in 
the study. The inclusion criteria were the following, according to the European Guidelines (5): i) diagnosed coronary artery disease; ii) exposure to minimum two cardiovascular risk factors: dyslipidemia (total cholesterol $>200 \mathrm{mg} / \mathrm{dl}$, LDL-cholesterol $>100 \mathrm{mg} / \mathrm{dl}$, HDL-cholesterol $<40 \mathrm{mg} / \mathrm{dl}$ for males and $<50 \mathrm{mg} / \mathrm{dl}$ for females, triglycerides $>150 \mathrm{mg} / \mathrm{dl}$ or normal lipid profile under cholesterol lowering medication), high blood pressure ( $>140 / 90 \mathrm{mmHg}$ or normal blood pressure under medication), diabetes mellitus, family history of cardiovascular disease at young age $(<50$ year-old for male relatives or at climax for female relatives), smoking, overweight (BMI between 25-29.9) or obesity (BMI >30).

Anamnesis helped us extract the following information: symptoms, family history (CAD, stroke, lower extremity artery disease and other consequences of severe atherosclerosis), personal cardiovascular history, work exposure to toxic substances and smoking habit.

Through clinical examination (for the BMI calculation) weight and height, blood pressure, heart rate and cardiac ascultation were recorded.

Basic haematological and biochemical blood analysis included: Red blood cell count, haemoglobin, mean haemoglobin concentration, mean erythrocyte volume, white blood cell count and leucocitary formula, platelet count, mean platelet volume, inflamatory markers [erythrocyte sedimentation rate $(\mathrm{ESR})$; $\mathrm{C}$ reactive protein $(\mathrm{CRP})$; fibrinogen $(\mathrm{Fg})]$, glycemia, glicated haemoglobin, lipid profile (total cholesterol, LDL cholesterol, HDL cholesterol, triglycerides), renal function (urea, creatinine), liver function (AST, ALT), cardiac necrosis enzymes (CK-MB, LDH, TGO).

An electrocardiogram was recorded for each patient (for rythm, ST segment and T wave analysis) and echocardiography (for ejection fraction, left ventricle contractility, cardiac dimension and valve analysis) was performed.

All patients underwent coronary angiography in order to adequately define the coronary status and those who met the criteria from the revascularisation guidelines, were implanted percutaneous stents in order to restore myocardial perfusion.

Apart from the blood for standard analysis, 2 extra mililiters of blood for genetic analysis was also collected for the determination of angiotensin-converting enzyme gene polymorphisms, deletions or insertions of genes.

Polymerase chain reaction (PCR) was used for the amplification of genetic material. The method is based on the DNA-polymerase ability to synthesize new strands of complementary DNA, starting from a base chain. DNA-polymerase can only add nuleotide to a pre-existing 3'-OH group, so it takes a primer to add the first nucleotide. In the end, the amplified sequence will be found in billions of copies. The process has several stages: DNA distortion, bonding of primers, extension of primers and consists of several cycles.

To determine the genetic polymorphism of the ACE gene, the MutaGel ACE kit was used. It determines mutations such as insertions (I)/deletions (D) based on analysis of the ALU sequence at intron 16. A kit allows 24 determinations. The MutaGel ACE kit contains specific primers for identifying both mutations: I-allele (fragment 490 bp) and D-allele (190 bp fragment), master mixture (Master Mix) for chain polymerization (Taq enzyme, $\mathrm{MgCl}_{2}$, dNTP, buffer solution), positive control for genotypes containing I-allele, positive control for genotypes containing D-allele, negative controls and high purity solution for PCR. In addition to this kit KBR3005 DNA extraction kit and gel electrophoresis reagents were also used. In the first stage, the purity and concentration of the DNA was checked. Then the following amplification program was used: initial hold step (initial distortion) at 95 degrees for $5 \mathrm{~min}$, followed by 30 exponential amplification cycles, each cycle having 3 temperature variations (distortion at 94 degrees for $60 \mathrm{sec}$, hybridization at 57 degrees for $60 \mathrm{sec}$ and elongation at 72 degrees for $90 \mathrm{sec}$ ) and final hold step 72 degrees 5 min and then 4 degrees. Next the amplified material was separated by electrophoresis in the $1.5 \%$ agarose gel, coloring SYBR Green fluorochrome fragments and analyzing them using UV spectrophotometry with $312 \mathrm{~nm}$ wavelengths. Finally, the identification of the fragments was made by comparing them with the DNA ladder.

Statistical analysis was performed using SPSS 18.0. Primary processing, i.e. data systematization through centralization and grouping, led to the obtaining of primary indicators, which are presented in the form of absolute sizes. On the basis of the primary indicators, different statistical processes of comparison, abstraction and generalization were obtained of the derivative indicators. Derivative indicators are intended to highlight the qualitative aspects of an ensemble, targeting the relationship between different parts of a group of patients or different characteristics, interdependence links between variables. The following derivative indicators were used, described by the ANOVA test: Indicators of the mean value (simple arithmetic mean, median, module, minimum and maximum values) and indicators of dispersion (standard deviation, coefficient of variation). The following statistical tests and correlation methods were also used: i) Chi-square test, qualitative non-parametric test, compares frequency distributions. ii) Student's t-test, parametric test that compares the average values recorded in 2 groups with normal distributions. iii) The F test (ANOVA) used when comparing 3 or more groups with normal distributions. iv) The Kruskall-Wallis correlation compares ordinal variables in 3 or more groups. v) Correlation coefficient 'Pearson' ( $r$ ) is the correlation of 2 variables in the same group, the direct/indirect correlation given by the coefficient sign.

\section{Results}

The patients were divided into four groups, according to the severity of the CAD, as revealed by the coronary angiography: 0C (non-significant stenosis, considered control group); 1C (one-vessel disese); 2C (two-vessel disease); and 3C (three-vessel disease).

The sex distribution revealed that patients were predominantly males $(74 \%)$, sex ratio $\mathrm{M} / \mathrm{F}=2.85 / 1$, regardless of the coronary status (Chi-square $=1.688 ; \mathrm{df}=3 ; \mathrm{P}=0.640)($ Fig. 1).

Age ranged between 35 and 85, the group mean was $64.5 \pm 10,85$ years, slightly elevated for the one-vessel disease patients (65.44 years; $\mathrm{P}=0.931)$ (Table I).

Women with altered coronary status were older than those in the control group ( $\mathrm{P}>0.05)$ (Fig. 2).

In conjunction with the average age of the study group ( 65 years), the age group distribution shows a $62.5 \%$ share of patients in group $1 \mathrm{C}$ over 65 years of age, while in group $3 \mathrm{C}$ the 
Table I. Age descriptive indicator (years) comparison between groups.

\begin{tabular}{|c|c|c|c|c|c|c|c|c|c|}
\hline \multirow[b]{2}{*}{ Group } & \multirow[b]{2}{*}{$\mathrm{N}$} & \multirow[b]{2}{*}{ Mean } & \multirow{2}{*}{$\begin{array}{l}\text { Standard } \\
\text { deviation }\end{array}$} & \multirow{2}{*}{$\begin{array}{c}\text { Standard } \\
\text { error }\end{array}$} & \multicolumn{2}{|c|}{ Confidence interval $95 \%$} & \multirow[b]{2}{*}{ Min } & \multirow[b]{2}{*}{ Max } & \multirow[b]{2}{*}{ Test F (ANOVA) P-value } \\
\hline & & & & & $-95 \% \mathrm{CI}$ & $+95 \% \mathrm{CI}$ & & & \\
\hline OC & 24 & 64.13 & 14.21 & 2.90 & 58.12 & 70.13 & 36 & 78 & 0.931 \\
\hline $1 \mathrm{C}$ & 48 & 65.44 & 9.53 & 1.38 & 62.67 & 68.20 & 35 & 85 & \\
\hline $2 \mathrm{C}$ & 48 & 64.21 & 12.29 & 1.77 & 60.64 & 67.78 & 34 & 80 & \\
\hline $3 \mathrm{C}$ & 34 & 64.15 & 7.70 & 1.32 & 61.46 & 66.83 & 44 & 76 & \\
\hline Total & 154 & 64.56 & 10.85 & 0.87 & 62.84 & 66.29 & 34 & 85 & \\
\hline
\end{tabular}

0C, non-significant stenosis, considered control group; $1 \mathrm{C}$, one-vessel disese; $2 \mathrm{C}$, two-vessel disease; and 3C, three-vessel disease.

Table II. Group structure according to age.

\begin{tabular}{|c|c|c|c|c|c|c|c|c|}
\hline \multirow[b]{2}{*}{ Age group } & \multicolumn{2}{|c|}{$0 \mathrm{C}$} & \multicolumn{2}{|c|}{$1 \mathrm{C}$} & \multicolumn{2}{|c|}{$2 \mathrm{C}$} & \multicolumn{2}{|c|}{$3 \mathrm{C}$} \\
\hline & $\mathrm{n}$ & $\%$ & $\mathrm{n}$ & $\%$ & $\mathrm{n}$ & $\%$ & $\mathrm{n}$ & $\%$ \\
\hline$<65$ years & 9 & 37.5 & 18 & 37.5 & 21 & 43.8 & 16 & 47.1 \\
\hline$\geq 65$ years & 15 & 62.5 & 30 & 62.5 & 27 & 56.2 & 18 & 52.9 \\
\hline
\end{tabular}

0C, non-significant stenosis, considered control group; 1C, one-vessel disese; 2C, two-vessel disease; and 3C, three-vessel disease.

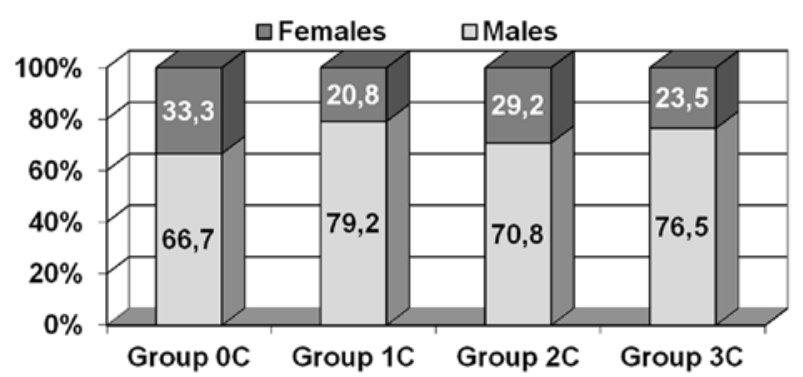

Figure 1. Sex distribution within groups (0C, non-significant stenosis, considered control group; $1 \mathrm{C}$, one-vessel disese; $2 \mathrm{C}$, two-vessel disease; and 3C, three-vessel disease).

frequency of patients under 65 years of age was $47.1 \%$. However, these frequency distributions showed no statistically significant differences, suggesting the homogeneity of the study group by age group (Chi-square $=1.007 ; \mathrm{df}=3 ; \mathrm{P}=0.800$ ) (Table II).

The identification of ACE genotypes was carried out according to the length of the amplicons after migration into the gel. The $190 \mathrm{bp}$ amplicon signals the presence of allele D and the $480 \mathrm{bp}$ amplicon signals the presence of allele I. Positive control is heterozygous. The three possible genotype variants: II, ID and DD were identified (Fig. 3). In the OC group 21 patients with genotype II, 3 patients with genotype ID and no patients with genotype DD were identified. In the $1 \mathrm{C}$ group 8 patients with genotype II, 40 patients with genotype ID and no patients with genotype $\mathrm{DD}$ were identified. In the $2 \mathrm{C}$ group 4 patients with genotype II, 36 patients with genotype ID and 8 patients with genotype DD were identified. In the $3 \mathrm{C}$ group no patients with genotype II, 6 patients with genotype ID and 28 patients with genotype DD were identified.

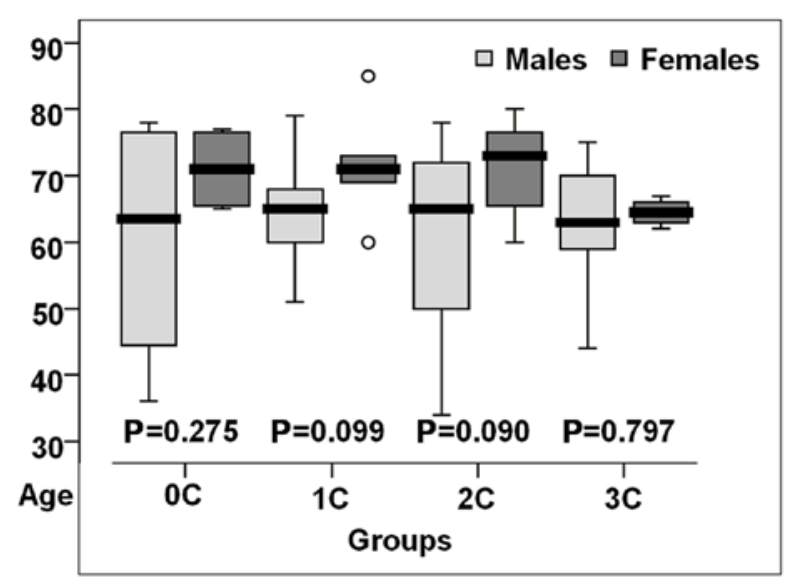

Figure 2. Comparison of mean age values between study groups (0C, non-significant stenosis, considered control group; $1 \mathrm{C}$, one-vessel disese; $2 \mathrm{C}$, two-vessel disease; and 3C, three-vessel disease).

The exposure to cardiovascular risk factors of DD patients with severe coronary lesions: in the $3 \mathrm{C}$ group $82.4 \%$ of patients had the genotype DD, $82.1 \%$ were male, $57.1 \%$ were $>65$ years of age, all with dyslipidemia, $92.9 \%$ diabetics and $57.1 \%$ were obese, half were smokers (Table III).

\section{Discussion}

Coronary artery disease is a polygenic pathology. Its onset and severity depend on the interaction between genetic and environmental factors. The DD, ID and II genotypes are associated with high, intermediate and low levels of ACE. Our study shows that the three genotypes influence the severity of CAD, interacting with conventional risk factors. The relationship 
Table III. Genotype-phenotype correlations for each study group.

\begin{tabular}{|c|c|c|c|c|c|c|c|c|}
\hline \multirow[b]{2}{*}{ Risk factor } & \multicolumn{4}{|c|}{ Group 0C $(n=24)$} & \multicolumn{4}{|c|}{ Group 1C $(n=48)$} \\
\hline & II $(n=21)$ & ID $(n=3)$ & $\mathrm{DD}(\mathrm{n}=0)$ & P-value & II $(n=8)$ & ID $(n=40)$ & $\mathrm{DD}(\mathrm{n}=0)$ & P-value \\
\hline Male & 76.2 & - & - & 0.006 & 75.0 & 80.0 & - & 0.755 \\
\hline$>65$ years & 57.1 & 100.0 & - & 0.080 & 50.0 & 65.0 & - & 0.430 \\
\hline Diabetes & 19.0 & - & - & 0.278 & 100.0 & 55.0 & - & 0.004 \\
\hline Dyslipidemia & 81.0 & 100.0 & - & 0.278 & 100.0 & 80.0 & - & 0.073 \\
\hline Obesity & 71.4 & 100.0 & - & 0.028 & 100.0 & 50.0 & - & 0.001 \\
\hline \multirow[t]{2}{*}{ Smoking } & 23.8 & - & - & 0.219 & 37.5 & 55.0 & - & 0.364 \\
\hline & \multicolumn{4}{|c|}{ Group 2C (n=48) } & \multicolumn{4}{|c|}{ Group 3C (n=34) } \\
\hline Risk factor & II $(n=4)$ & ID $(n=36)$ & $\mathrm{DD}(\mathrm{n}=8)$ & P-value & II $(\mathrm{n}=0)$ & ID $(n=6)$ & $\mathrm{DD}(\mathrm{n}=28)$ & P-value \\
\hline Male & 100.0 & 61.1 & 100.0 & 0.007 & - & 50.0 & 82.1 & 0.113 \\
\hline$>65$ years & 100.0 & 41.7 & 100.0 & 0.001 & - & 33.3 & 57.1 & 0.287 \\
\hline Diabetes & - & 44.4 & 100.0 & 0.001 & - & 100.0 & 92.9 & 0.370 \\
\hline Dyslipidemia & 100.0 & 88.9 & 100.0 & 0.298 & - & 100.0 & 100.0 & 1.000 \\
\hline Obesity & - & 61.1 & 100.0 & 0.001 & - & 100.0 & 57.1 & 0.012 \\
\hline Smoking & 100.0 & 47.2 & 25.0 & 0.022 & - & - & 50.0 & 0.007 \\
\hline
\end{tabular}

0C, non-significant stenosis. considered control group; 1C, one-vessel disease; 2C, two-vessel disease; and 3C, three-vessel disease.

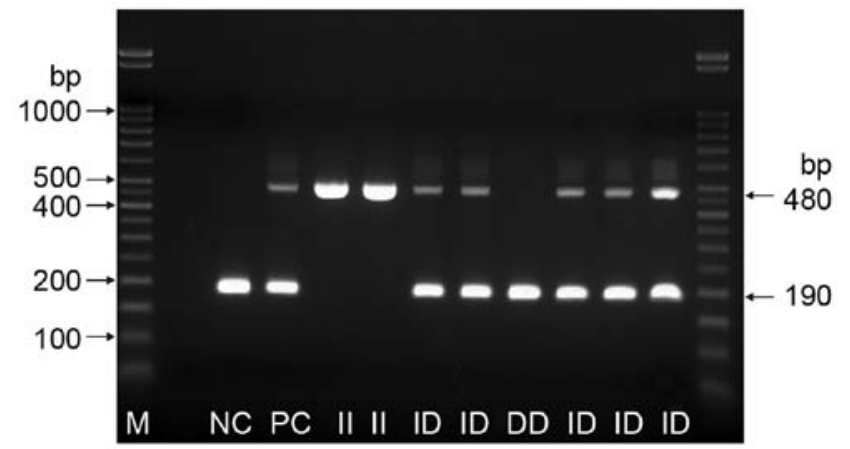

Figure 3. ACE amplicon migration in gel electrophoresis: M (DNA ladder), NC (negative control), PC (positive control), II (480 bp), ID (480/190 bp) and DD (190 bp). ACE, angiotensin-converting enzyme.

between CAD and genetic polymorphism (genotype DD) was first discussed by Cambien et al (6). Since then, the topic has long been debated, the results are still unclear, with some positive studies $(7)$, and others negative $(8,9)$. Polymorphism I/D is responsible for $20-50 \%$ of the differences in plasma level of ACE, which assumes that 50-80\% come from the influence of environmental factors or from the interaction between these polymorphisms and environmental factors (6). Our results in this direction are indisputable, since we demonstrated a growing precentage of the genotype DD proportional with the growing severity of the coronary disease, from absent genotype DD in the no-vessel disease, to $82.5 \%$ DD carriers among the three-vessel disease patients. Also, II genotype, which was predominant in the control group, was absent among the $3 \mathrm{C}$ patients, who were all D-allele carriers (17.64\% genotype ID and $82.35 \%$ genotype DD). This was similar to the results of
Nakai et al (10), Vargas-Alarcón et al (11) Jamil et al (12) and Acarturk et al (13), who demonstrated an association between CAD and ACE gene I/D polymorphism. By contrast, Ragia et al (14), Qiu et al (15), and Ramakrishnan et al (16) found no association between those two parameters.

Traditional risk factors such as smoking, high blood pressure, diabetes mellitus, family history of cardiovascular disease at a young age, obesity influence RAAS by stimulating ACE synthesis, leading to excessive vasoconstriction, enhancing ischemic risk. Freitas et al (17) concluded that genotype DD induces onset and severity of coronary lesions only when exposure to common risk factors is present, like hypertension and diabetes. Also, the case control study of Niemec et al (18) demonstrated correlations between ACE gene polymorphisms and CAD in the presence of hypercholesterolemia. The present study revealed that three-vessel disease genotype DD patients were diabetic and dyslipidemic and half of them were obese and heavy smokers.

The present study has some limitations. First, the sample size of included patients is small, that may reduce the statistical power. Second, this is a single-center clinical study, which might cause some selection bias.

In conclusion, by analysing all the study groups, significant associations were obtained between the D-allele and male sex, age over 65 years, smoking, diabetes mellitus, obesity, dyslipidemia, which illustrates the strong interaction between ACE polymorphism and environmental factors (genetic-epigenetic interaction) in initiation and worsening of coronary heart disease. Based on this study it is concluded that the D-allele is associated with a greater risk for acute coronary events and severe coronary stenosis, especially when risk genotype and risk phenotype interact. 


\section{Acknowledgements}

Not applicable.

\section{Funding}

The present study was supported by the European Social Fund, Human Resources Development Operational Programme 2007-2013 (project no. POSDRU/159/1.5/S/133377).

\section{Availability of data and materials}

The datasets used and/or analyzed during the current study are available from the corresponding author on reasonable request.

\section{Authors' contributions}

MCV and IBB acquired the data. MCV, IBB, OVB and AB analyzed the data and drafted the manuscript. MB, MC and CAG designed the study and supervised data analysis. MCV, MCB and DI were involved in the design of the study and analyzed the data. All authors read and approved the final manuscript.

\section{Ethics approval and consent to participate}

The study was approved by the Ethics Committee of the 'Grigore T. Popa' University of Medicine and Pharmacy (Iasi, Romania) on 09.06 .2015 , according to the law of medical research, no. 206 from 27.05.2004. Informed consent was obtained from all patients included in the study.

\section{Patient consent for publication}

Not applicable.

\section{Competing interests}

The authors declare that they have no competing interests.

\section{References}

1. Chen YH, Liu JM, Hsu RJ, Hu SC, Harn HJ, Chen SP, Jeng JR, Wu CL, Ho JY and Yu CP: Angiotensin converting enzyme DD genotype is associated with acute coronary syndrome severity and sudden cardiac death in Taiwan: A case-control emergency room study. BMC Cardiovasc Disord 12: 6, 2012.

2. Sayed-Tabatabaei FA, Oostra BA, Isaacs A, van Duijn CM and Witteman JCM: ACE polymorphisms. Circ Res 98: 1123-1133, 2006.

3. Pfohl M, Koch M, Prescod S, Haase KK, Häring HU and Karsch KR: Angiotensin I-converting enzyme gene polymorphism, coronary artery disease and myocardial infarction. An angiographically controlled study. Eur Heart J 20: 1318-1325, 1999.

4. Hubert C, Houot AM, Corvol P and Soubrier F: Structure of the angiotensin I-converting enzyme gene. Two alternate promoters correspond to evolutionary steps of a duplicated gene. J Biol Chem 266: 15377-15383, 1991.
5. Windecker S, Kolh P, Alfonso F, Collet JP, Cremer J, Falk V, Filippatos G, Hamm C, Head SJ, Jüni P, et al; Authors/Task Force members: 2014 ESC/EACTS Guidelines on myocardial revascularization: The Task Force on Myocardial Revascularization of the European Society of Cardiology (ESC) and the European Association for Cardio-Thoracic Surgery (EACTS)Developed with the special contribution of the European Association of Percutaneous Cardiovascular Interventions (EAPCI). Eur Heart J 35: 2541-2619, 2014.

6. Cambien F, Costerousse O, Tiret L, Poirier O, Lecerf L, Gonzales MF, Evans A, Arveiler D, Cambou JP and Luc G: Plasma level and gene polymorphism of angiotensin-converting enzyme in relation to myocardial infarction. Circulation 90: 669-676, 1994

7. Gardemann A, Fink M, Stricker J, Nguyen QD, Humme J, Katz N, Tillmanns H, Hehrlein FW, Rau M and Haberbosch W: ACE I/D gene polymorphism: Presence of the ACE D allele increases the risk of coronary artery disease in younger individuals. Atherosclerosis 139: 153-159, 1998.

8. Ferrières J, Ruidavets JB, Fauvel J, Perret B, Taraszkiewicz D, Fourcade J, Niéto M, Chap H and Puel J: Angiotensin I-converting enzyme gene polymorphism in a low-risk European population for coronary artery disease. Atherosclerosis 142: 211-216, 1999.

9. Canavy I, Henry M, Morange PE, Tiret L, Poirier O, Ebagosti A, Bory $M$ and Juhan-Vague I: Genetic polymorphisms and coronary artery disease in the south of France. Thromb Haemost 83: 212-216, 2000.

10. Nakai K, Itoh C, Miura Y, Hotta K, Musha T, Itoh T, Miyakawa T, Iwasaki $\mathrm{R}$ and Hiramori K: Deletion polymorphism of the angiotensin I-converting enzyme gene is associated with serum ACE concentration and increased risk for CAD in the Japanese. Circulation 90: 2199-2202, 1994.

11. Vargas-Alarcón G, Zamora J, Sánchez-García S, Rodríguez-Pérez JM, Cardoso $\mathrm{G}$ and Posadas-Romero C: Angiotensin-I-converting enzyme (ACE) insertion/deletion polymorphism in Mexican patients with coronary artery disease. Association with the disease but not with lipid levels. Exp Mol Pathol 81: 131-135, 2006.

12. Jamil K, Syed R and Rao H: Implications of I/D (rs4340) polymorphism in CAD among South Indian population. Int J Med Med Sci 1: 151-157, 2009.

13. Acarturk E, Attila G, Bozkurt A, Akpinar O, Matyar S and Seydaoglu G: Insertion/deletion polymorphism of the angiotensin converting enzyme gene in coronary artery disease in southern Turkey. J Biochem Mol Biol 38: 486-490, 2005.

14. Ragia G, Nikolaidis E, Tavridou A, Arvanitidis KI, Kanoni S, Dedoussis GV, Bougioukas G and Manolopoulos VG: Renin-angiotensin-aldosterone system gene polymorphisms in coronary artery bypass graft surgery patients. J Renin Angiotensin Aldosterone Syst 11: 136-145, 2010.

15. Qiu C, Han Z, Lu W and Zhang C: Association of polymorphisms in angiotensin-converting enzyme and type 1 angiotensin II receptor genes with coronary heart disease and the severity of coronary artery stenosis. J Huazhong Univ Sci Technolog Med Sci 27: 660-663, 2007

16. Ramakrishnan V, Jaikumar V, Gowtham Kumar S, Thiyagarajan G and Vincent S: Angiotensin-converting enzyme gene polymorphism in patients with coronary artery disease. J Adv Lab Res Biol 1: 36-40, 2010.

17. Freitas AI, Mendonça I, Brión M, Sequeira MM, Reis RP Carracedo A and Brehm A: RAS gene polymorphisms, classical risk factors and the advent of coronary artery disease in the Portuguese population. BMC Cardiovasc Disord 8: 15, 2008.

18. Niemiec P, Zak I and Wita K: Modification of the coronary artery disease risk associated with the presence of traditional risk factors by insertion/deletion polymorphism of the ACE gene. Genet Test 11: 353-359, 2007. 